\title{
Multivariate linear regression model of paste thickener
}

\author{
Jari Ruuska ${ }^{1}$ Eemeli Ruhanen ${ }^{2}$ Janne Kauppi ${ }^{3}$ Sakari Kauvosaari ${ }^{3}$ Mika Kosonen ${ }^{3}$ \\ ${ }^{1}$ Control Engineering, University of Oulu, Finland, jari.ruuska@oulu.fi \\ ${ }^{2}$ Yara Suomi Oy, Siilinjärvi Mill, Finland \\ ${ }^{3}$ Outotec (Finland) Oy, Finland
}

\begin{abstract}
The world is using a lot of materials in the day-to-day life. This requires a lot of mining of the ores from the ground. As the amount of ore is remarkable, also the amount of waste rock and for that reason the amount of the tailings is huge. The water content of the tailings is a subject to decrease. One potential technology for that is a paste thickener. In this paper, a multivariate linear regression model using paste line pressure difference as an output variable is described. The model can be utilized for the development of a new control strategy. Another model was formed using rake torque as an output variable.
\end{abstract}

Keywords: paste thickener, multivariate linear regression, pressure difference, rake torque

\section{Introduction}

Modern world relies on materials. Saying: "What you can't grow, you need to dig" still stands meaning that people need different kind of materials to make the products and the necessities for their everyday life. Caused by this fact, mining is a very important industry branch. Due to that, it needs to be made as efficient as possible. Together with the increase of the tonnage of the rock crushed, the amount of the waste rock also increases. The tailings from a flotation circuit contain a remarkable amount of water and if the water content can be lowered, the required area of tailings pond can be decreased. Due to constantly, more and more strict getting environmental permissions make this kind of development favourable. One way to do this is to add a paste thickener into the process chain. Thickening is a most economical method within the several dewatering techniques. The thickening process normally occurs in the large-diameter tanks where the solids particles settle under the influence of gravity, i.e. sedimentation. Adiguzel and Bascetin (2019) study the flow behaviour of the paste tailings, which consists of different pulp densities, was studied to define the effect of the particle size distribution of the tailings on a surface paste disposal. So to speak, the rheological behaviour of the tailings was examined. Jewell et al. (2002) raise a question into the discussion: the operation of the paste thickeners has different practical problems. One of them is a narrow operating window as a small change in the underflow solids concentration may have a major impact on the properties (for example pumpability and flowability) of the underflow. Due to these issues, the control of the paste thickener can be challenging. The out coming paste is from time to time challenging to operate. At the worst, it causes a clogging in the process. This causes more need for the maintenance and even downtime. To be able to avoid this scenario, the process needs to be known better and the control to be more derivative. Bürger et al. (2005) have formulated a mathematical model based on the balance equations to simulate the dynamics. Betancourt et al. (2014) present a one-dimensional model based on the two nonlinear partial differential equations. Gheshlaghi et al. (2013) introduce a model based on the computational fluid dynamics and the population balance models. Chai et al. (2016) propose a controller including an underflow slurry flowrate (USF) presetting unit via a one-step optimal proportional and integral (PI) control with the un-modelled dynamics compensation, a fuzzy reasoning based USF set-point compensator and a switching mechanism using rule based reasoning. Setiawan et al. (2013) introduce a model-based control (MPC), which shows a significant improvement to controllability in the simulations. Tan et al. (2015) propose a model and Kalman filter used to make a coal parameter estimation showing an improved control result on the underflow solids concentration. Tan et al. (2016) present a MPC with the changing dynamics to handle fast, moderate and slow variables using the changing optimization horizon. Tan et al. (2017) introduce an additional rake torque constraint model to an earlier developed MPC to regulate further the underflow solids concentration and to prevent the rake liftings and the pumping problems. Tippett et al. (2014) propose a MPC with a changing sampling rate; the nearer steps had a shorter sampling rate than those in the distant future. This kind of an approach gives a possibility to fine-tune the control trajectory in the near horizon and still allows a long prediction and the control horizons for the slow dynamics. Xu et al. (2015) discuss a control strategy based on a mass balance model and the expert rules. 
A multivariate linear regression model using paste line pressure difference as an output variable is presented.

\section{Materials and methods}

\subsection{Process description}

Only EU-area's phosphate mine, which is operated by Yara, is located at Siilinjärvi, Finland. The product of the ore extracted from the open pits is apatite concentrate, from which the fertilizers and phosphoric acid are the final products. The total ore mining annually is $11 \mathrm{Mt}$ and the production of the apatite concentrate is $1 \mathrm{Mt}$.

The solids content of slurry increases typically in the thickeners. A clean overflow and the maximum solids concentration in the underflow are the general objectives. The agglomerates of the solids are formed by using the flocculants to increase the settling rate and thus to improve the overflow clarity. A very high online availability is typical for the thickeners' operation. Many industry branches use these vessels.

A thickener used in the mineral processing is introduced in Figure 1. The flocculants rate and the underflow rate are the two independent variables, which are typically used for the control. The feed rate is only used in an emergency situation to avoid the disturbances to the plant production. The dependent variables are for example rake torque, underflow density, overflow turbidity, solids interface level (bed depth), solids inventory (bed pressure), solid settling rate and underflow viscosity. (Bergh et al., 2015)

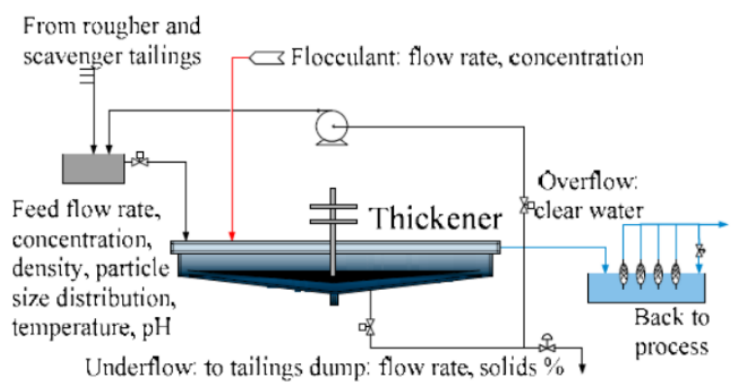

Figure 1. Typical thickener used in mineral processing

\subsection{Process data}

The data set used for the data-analysis contains data from Yara's both paste thickeners, but after discussing with the plant experts the data-analysis was limited only to the thickener one. The whole data set contained altogether 73 measurements from February -17 to February -18 . The frequency of the measurements was one minute. An MPC-controller to reduce the underflow density variation is presented in Kosonen et al. (2017).
As the process data was used, a normal pre-processing procedure was needed. The rows containing NaN (not a number) were removed. The periods, when the values of the pressure difference of paste line (i.e. response variable) were not changing, were removed. Four feed and three thickener 1 measurements were delayed eight hours. The delay was defined by the plant experts. The definition was based on their process knowledge. The size of the data set was 265000 rows; from which 130000 was chosen for the training and 135000 for the testing. The amount of the variables chosen for the modelling was sixteen; the selection was based on the data-analysis (reported elsewhere) and the plant expert knowledge.

\subsection{Modelling}

Multivariate linear regression (MLR) model is given by

$$
\hat{y}=b_{0}+b_{1} x_{1}+b_{2} x_{2}+\ldots+b_{M} x_{M}=b_{0}+\sum_{j=1}^{M} b_{j} x_{j},
$$

where $y$ is the output variable that is predicted, $x_{j}$ are the input variables and $b_{j}$ are the unknown model parameters. As the name indicates, MLR models are able to map the linear interactions variables. The model may also include the interaction and quadratic terms. A more detailed description on MLR can be found for example from Rencher and Christensen (2012).

\subsection{Variable reduction}

The variable reduction is done based on the statistics using p-value as an indicator. The smaller the p-value, the higher the significance of the variable is for the result. The reduction of the variables is executed so that after the first modelling round, the variable with the biggest p-value is removed and then the modelling is done again and the next variable is removed based on p-value. The procedure is repeated as long as the modelling result is improving.

\subsection{Modelling objective}

The modelling objective for this study was to model the paste thickener process using paste line pressure difference as an output variable. The changes in this variable give good information of the status of process and the material in the thickener. The rise in the pressure difference often is an indicator that the problems in the controllability of the process will occur or at least the probability for them is arising. To be able to predict this, a good model of a process is needed. Another model was formed using the same, reduced variable set as for the first model; the output variable was rake torque. 


\subsection{Static and dynamic model}

The basic multivariate linear regression model is called a static model. The static model considering the average error of the previous ten data points is called a dynamic model.

\section{Results and discussion}

\subsection{Paste line pressure difference model}

The first modelling result for the training data with the sixteen variables is presented in Figure 2. As it can be seen, the variation is quite remarkable.
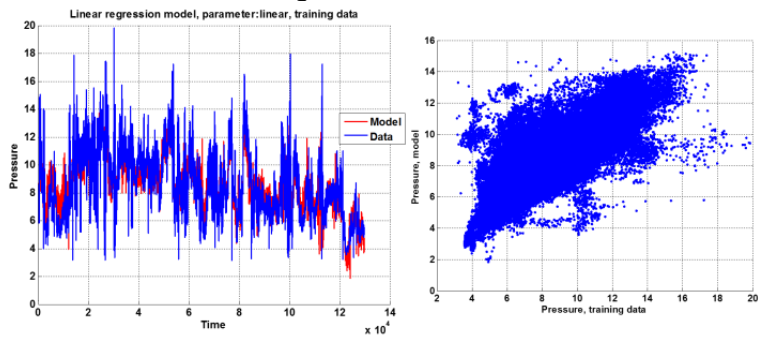

Figure 2. Model result for training data with sixteen variables

The test figures for the models with sixteen and six variables are presented in Figure 3. The variation of the six variables model is a bit smaller and it can follow the changes in the process circumstances a bit better. Still the variation is remarkable.
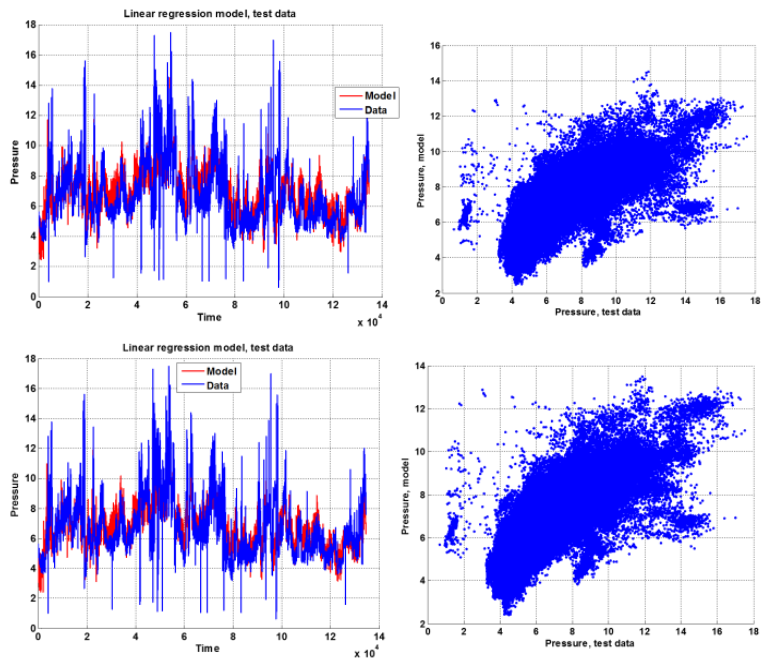

Figure 3. Test figures with 16 and 6 variables.

For the six variables model two further versions was done. The interaction and quadratic terms were allowed in those models. The test figures are presented in Figure 4. The variations are remarkable.
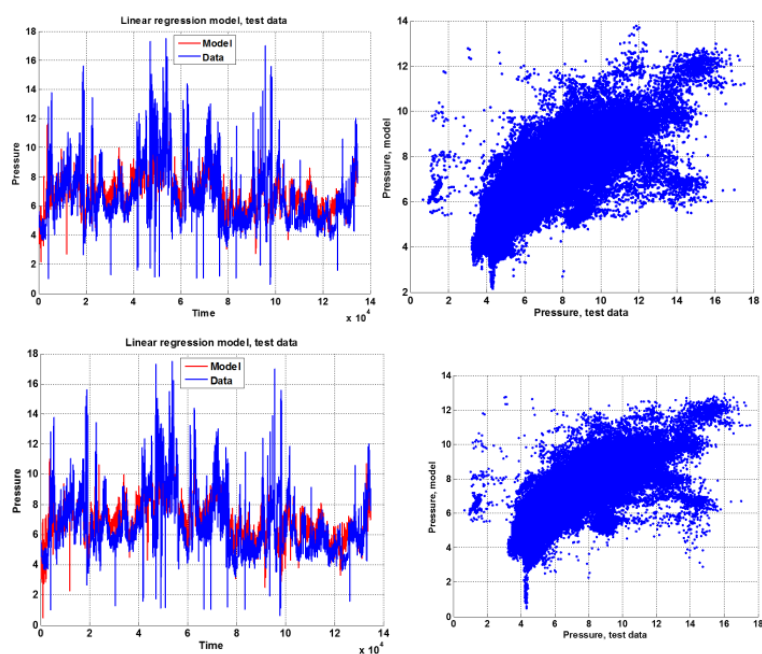

Figure 4. Test figures of six variable models with interaction and quadratic terms

The modelling error summary for the different models is given in Table 1.

Table 1. Modelling error summary

\begin{tabular}{|c|c|c|}
\hline Model & $\begin{array}{c}\text { Average error, } \\
\text { training }\end{array}$ & $\begin{array}{c}\text { Average error, } \\
\text { test }\end{array}$ \\
\hline 16 variables & 1,0971 & 1,0518 \\
\hline 13 variables & 1,1091 & 1,0597 \\
\hline 12 variables & 1,1102 & 1,0623 \\
\hline 11 variables & 1,1099 & 1,0574 \\
\hline 10 variables & 1,1084 & 1,0157 \\
\hline 9 variables & 1,1157 & 1,0041 \\
\hline 8 variables & 1,1150 & 1,0062 \\
\hline 7 variables & 1,1190 & 1,0082 \\
\hline
\end{tabular}

As the modelling result didn't improve remarkably by reducing the variables, it was considered that something else should be done. As a one possibility, it was seen that the short term changes in the process are not captured by the current model structure and it could be handled by using a simple ten previous data points' error average addition to the model result. The five variables model test figures for a static and a dynamic model are presented in Figure 5. The model performance is improved quite considerably. The performance can be found in Table 2 .
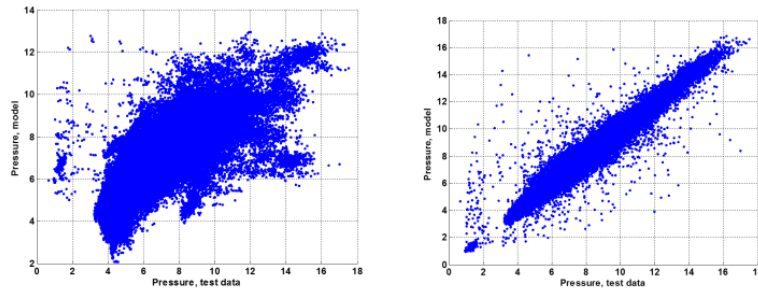

Figure 5. Test figures of static and dynamic model 
Table 2. Comparison of a static and a dynamic model

\begin{tabular}{|c|c|c|}
\hline Model & \multicolumn{1}{|c|}{$\begin{array}{c}\text { Error, } \\
\text { training }\end{array}$} & \multicolumn{1}{c|}{$\begin{array}{c}\text { Error, } \\
\text { test }\end{array}$} \\
\hline 5 variables_static & 1,1512 & 1,0012 \\
\hline 5variables_dynamic & 0,3186 & 0,2667 \\
\hline
\end{tabular}

\subsection{Rake torque model}

Another model was formed using rake torque as an output variable. The model has four variables and the model result of the training data can be seen in Figure 6. The figure of the test data is presented in Figure 7. The figures are presented from the dynamic models. The performance of the models can be found in Table 3 .

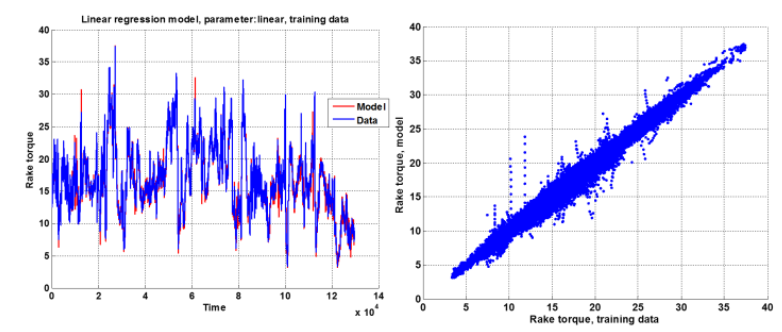

Figure 6. Model result of training data for dynamic model

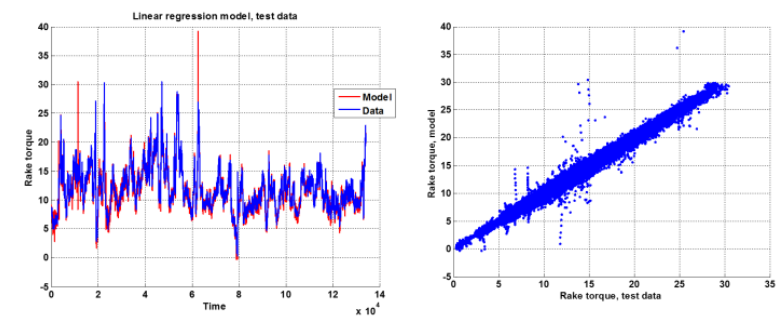

Figure 7. Test figures of dynamic model

Table 3. Comparison of static and dynamic model

\begin{tabular}{|l|c|c|}
\hline \multicolumn{1}{|c|}{ Model } & $\begin{array}{c}\text { Error, } \\
\text { training }\end{array}$ & $\begin{array}{c}\text { Error, } \\
\text { test }\end{array}$ \\
\hline Rake torque & 3,8441 & 3,9536 \\
\hline Rake torque_dynamic & 0,3361 & 0,3364 \\
\hline
\end{tabular}

Both models give satisfactory results, but there is still plenty room for the improvement. Therefore, other variables as an output variable should be tested, for example, the product of paste line pressure difference and rake torque or other combinations. Another modelling method should also be considered.

\section{Conclusions}

As the environmental permissions are getting stricter, it is important to make the processes in use as effective as possible. In this study, the paste thickener process was modelled using MLR-method. The modelling result was satisfactory. As a result from this study, the significant variables effecting on the paste line pressure difference were identified. This information can be utilized as an input for developing a new control strategy. It was still noticed that not all the needed variables were available for the modelling purposes. One of the phenomena, which are difficult to measure, is the changes in the rheology. It would be very useful to have a reliable measurement for it. The changes in the rheology can be quick and they have a significant effect on the pumpability of the paste. That kind of a measurement would be very useful on many different branches of the industry.

\section{Acknowledgements}

Acknowledgement for the funding of the study and the expertise during the execution is given to the staff of Outotec. The expertise given by the staff of Yara was also remarkable and it is acknowledged.

\section{References}

D. Adiguzel, A. Bascetin. The investigation of effect of particle size distribution on flow behavior of paste tailings Journal of Environmental Management, 243, 393-401, 2019. doi: 10.1016/j.jenvman.2019.05.039

L. Bergh, P. Ojeda and L. Torres. Expert control tuning of an industrial thickener, IFAC-PapersOnLine, 48, 86-91, 2015. doi: 10.1016/j.ifacol.2015.10.083

F. Betancourt, R. Bürger, S. Diehl and S. Farås. Modeling and controlling clarifier-thickeners fed by suspensions with time-dependent properties, Minerals Engineering, 62, 91-101, 2014. doi: 10.1016/j.mineng.2013.12.011

R. Bürger, K.H. Karlsen and J.D. Towers. Mathematical model and numerical simulation of the dynamics of flocculated suspensions in clarifier-thickeners, Chemical Engineering Journal, 111, 119-134, 2005. doi: 10.1016/j.cej.2005.02.007

T. Chai, Y. Jia, H. Li and H. Wang, H. An intelligent switching control for a mixed separation thickener process, Control Engineering Practice, 57, 61-71, 2016. doi: 10.1016/j.conengprac.2016.07.007

M.E. Gheshlaghi, A.S. Goharrizi, A.A. Shahrivar and H. Abdollahi. Modeling industrial thickener using computational fluid dynamics (CFD), a case study: Tailing thickener in the Sarcheshmeh copper mine, International Journal of Mining Science and Technology, 23, 885-892, 2013. doi: 10.1016/j.ijmst.2013.11.002

R.J. Jewell, A.B. Fourie and E.R. Lord. Paste and Thickened Tailings: A Guide. Australian Centre for Geomechanics, University of Western Australia, 2002.

M. Kosonen, S. Kauvosaari, S. Gao and B. Henriksson. Performance optimization of paste thickening, in A Wu \& R Jewell (eds), Proceedings of the 20th International Seminar on Paste and Thickened Tailings, University of Science and Technology Beijing, Beijing, China, 13-22, 2017. doi: 10.36487/ACG_rep/1752_02_Kosonen

A.C. Rencher and W.F. Christensen (2012) "Chapter 10, Multivariate regression - Section 10.1, Introduction", Methods of Multivariate Analysis, Wiley Series in Probability and Statistics, 709 (3rd ed.), John Wiley \& Sons. ISBN: 978-0-470-17896-6 
R. Setiawan, C.K. Tan, J. Bao and G. Bickert. Model Predictive Control of a Paste Thickener in Coal Handling and Preparation Plants, $10^{\text {th }}$ IFAC

International Symposium on Dynamics and Control of Process Systems, Mumbai, India, 247-252, 2013. doi: 10.3182/20131218-3-IN-2045.00123

C.K. Tan, R. Setiawan, J. Bao and G. Bickert, G. Studies on parameter estimation and model predictive control of paste thickeners, Journal of Process Control, 28, 1-8, 2015. doi: 10.1016/j.jprocont.2015.02.002

C.K. Tan, M.J. Tippett and J. Bao. Model predictive control with non-uniformly spaced optimization horizon for multi-timescale processes, Computers and Chemical Engineering, 84, 162-170, 2016. doi: 10.1016/j.compchemeng.2015.08.010

C.K. Tan, J. Bao and G. Bickert. A study on model predictive control in paste thickeners with rake torque constraint, Minerals Engineering, 105, 52-62, 2017. doi: 10.1016/j.mineng.2017.01.011

M.J. Tippett, C.K. Tan and J. Bao. Non-Constant PredictionStep MPC for Processes with Multi-Scale Dynamics, $19^{\text {th }}$ IFAC World Congress, Cape Town, South Africa, 3068-3073, 2014. doi: 10.3182/20140824-6-ZA1003.01093

N. Xu, X. Wang, J. Zhou, Q. Wang, W. Fang and X. Peng. An intelligent control strategy for thickening process, International Journal of Mineral Processing, 142, 56-62, 2015. doi: 10.1016/j.minpro.2015.01.007 